\title{
Ceramic Tiles Obtained from Clay Mixtures with the Addition of Diverse Metallurgical Wastes
}

\author{
Nancy Quaranta ${ }^{1}$, Marta Caligaris ${ }^{1}$, Miguel Unsen ${ }^{1}$, Hugo López ${ }^{1}$, \\ Gisela Pelozo ${ }^{1}$, Juan Pasquini ${ }^{1}$, Carlos Vieira ${ }^{2}$ \\ ${ }^{1}$ Grupo de Estudios Ambientales, Facultad Regional San Nicolás, Universidad Tecnológica Nacional, San Nicolás, Argentina \\ ${ }^{2}$ Laboratório de Materiais Avançados-LAMAV, Universidade Estadual do Norte Fluminense Darcy Ribeiro, \\ CCT/UENF, Campos dos Goytacazes, Río de Janeiro, Brasil \\ Email: nquaranta@frsn.utn.edu.ar
}

Received December 8, 2013; revised January 8, 2014; accepted January 15, 2014

Copyright (C) 2014 Nancy Quaranta et al. This is an open access article distributed under the Creative Commons Attribution License, which permits unrestricted use, distribution, and reproduction in any medium, provided the original work is properly cited. In accordance of the Creative Commons Attribution License all Copyrights (C) 2014 are reserved for SCIRP and the owner of the intellectual property Nancy Quaranta et al. All Copyright (C) 2014 are guarded by law and by SCIRP as a guardian.

\section{ABSTRACT}

The generation of industrial residues is unavoidable, but these materials may be recovered, redirecting them toward new production processes, rather than allocating them to the stream of discards. The aim of this paper is to study the feasibility of utilization of metallurgical wastes as raw material for tiles in the ceramic industry, using the residual materials as aggregates in clay based ceramics. The residues used are: sludge and slag from several metallurgical processes, Ruthner dust and foundry sand. Samples were obtained from mixtures of clay and each waste in various percentages, which were then heat treated. The pieces obtained were characterized using several techniques, with the aim of determining the properties of these materials in relation to the commercial requirements. A high feasibility of reuse of most of these wastes as raw material in the production of ceramic bodies has been established.

\section{KEYWORDS}

\section{Ceramics; Metallurgical Wastes; Recycling}

\section{Introduction}

The increase in the volume of industrial discards, the simultaneous reduction in waste disposal areas, and all the problems associated with industrial wastes, are issues that demand immediate attention.

The generation of industrial residues is unavoidable. Wastes are the last outcome of any industrial activity, but these materials may be recovered, redirecting them toward new production processes, rather than allocating them to the stream of discards.

The aim of this paper is to study the feasibility of utilization of metallurgical wastes as raw material for tiles in the ceramic industry, using the residual materials as aggregates in clay based ceramics. The residues used are: blast furnace sludge (BFS), converter steel slag (CSS), Ruthner dust (RD) and foundry sand (FS).

Diverse alternatives for the reutilization of these wastes have been analyzed. Other authors have studied the re- placement of sand in concrete mixtures, up to $30 \%$, by foundry sand $[1,2]$, the use of foundry sand in the construction of blast furnace channels [3] and the addition of foundry sand in ceramics [4].

The converter steel slag can be used in several areas, such as fertilizer [5], as aggregates in road construction [6], in cement [7] and as raw material for ceramics [8].

Ruthner dust is used, among other applications, in the manufacture of ferrites, as colorants for concrete and for catalysts [9].

Blast furnace sludge has been studied as adsorbent of heavy metals in aqueous effluents $[10,11]$ and as the main material of ceramic particles in filters for wastewater treatment [12].

\section{Experimental}

The raw materials used in this study, wastes and clay, are granular and have been characterized by diverse tech- 
niques: optical microscopy (OM), scanning electron microscopy (SEM) with X-ray electron dispersive analysis (EDS), differential and gravimetric thermal analyses (DTA-TGA) and particle size distribution, among others. The optical observations were made with Zeiss-Axiotech equipment with a Donpisha 3CCD camera and image scanner. SEM analyses were carried out through a Phillips 515 scanning electronic microscope with an X-ray detector (EDAX-Phoenix). DTA-TGA was performed in a Shimadzu DTA-50, TGA-50 with Thermal Analyzer TA-50 WSI.

Samples were obtained from mixtures of clay and each waste in various percentages. The particle sizes used were less than $2 \mathrm{~mm}$. A moisture content of $8 \%$ was added to these mixtures. The samples were obtained by uniaxial pressure of $25 \mathrm{MPa}$ in a rectangular mold of $40 \mathrm{~mm}$ x 70 $\mathrm{mm}$, resulting thickness of approximately $16 \mathrm{~mm}$.

These samples were then heat treated in the range $900^{\circ} \mathrm{C}-1000^{\circ} \mathrm{C}$, taking into account the phase diagrams corresponding to the mixtures compositions.

The obtained probes were characterized by diverse techniques: porosity, mechanical properties, SEM, OM, weight loss on ignition (LoI), permanent volumetric variation (PVV), among others.

The porosity of the samples was determined by the 12510 IRAM Standard.

The mechanical essays were carried out with a Cific
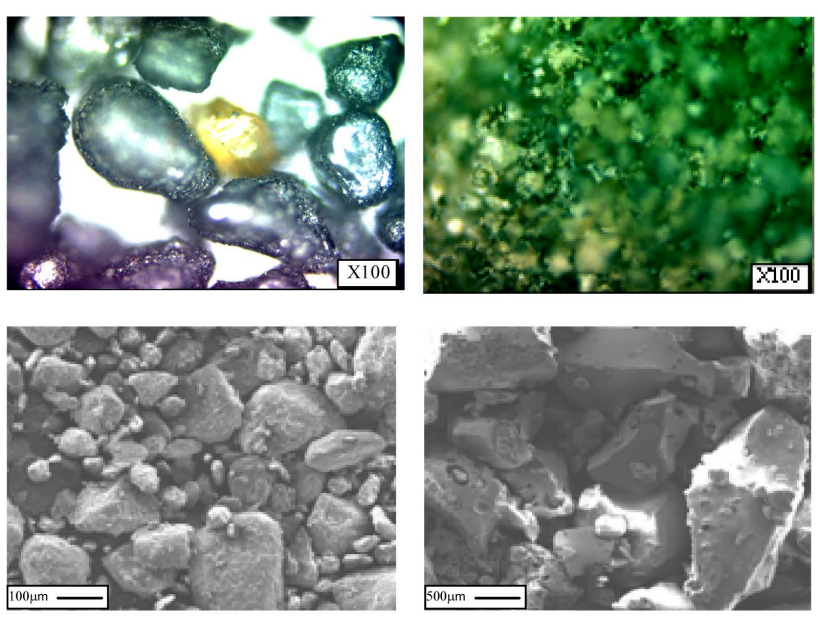

Foundry sand

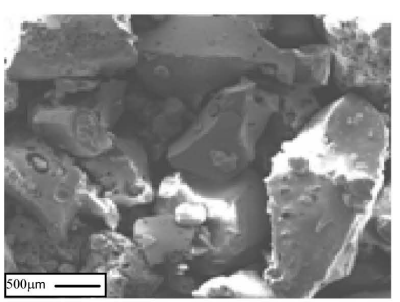

Converter steel slag

Universal Testing Machine, $294 \mathrm{kN}$. The bending test is performed on samples with the aspect ratio established in ASTM C67-03a Standard. LoI and PVV values were determined on the bricks samples by difference of weights and volumes respectively, before and after the heating treatment.

\section{Results and Discussion}

\subsection{Raw Materials Characterization}

The microscopic appearance of the wastes is shown in Figure 1.

The chemical composition of the studied wastes by EDS semiquantitative technique is presented in Table 1, expressed as a percentage of the present elements, regardless of carbon content. There is no $\mathrm{C}$ present in $\mathrm{RD}$ waste and in FS, CSS and BFS the C content was determined as $16.18 \%, 13.20 \%$ y $51 \%$, respectively. Figure 2 presents the DTA-TGA of these residues. The analysis corresponding to FS sample shows a notable weight loss between $400^{\circ} \mathrm{C}$ to $550^{\circ} \mathrm{C}$ with an exothermic peak in DTA in this range of temperatures. This is explained as the combustion reaction of the organic compounds used as additives during the fabrication process of foundry molds. A small endothermic peak at $572^{\circ} \mathrm{C}$ is also observed which corresponds to the reversible allotropic transformation of quartz (c.a. $\left.573^{\circ} \mathrm{C}\right)$ [13].
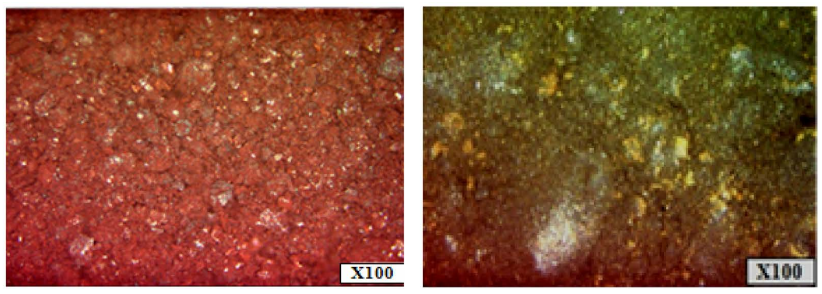

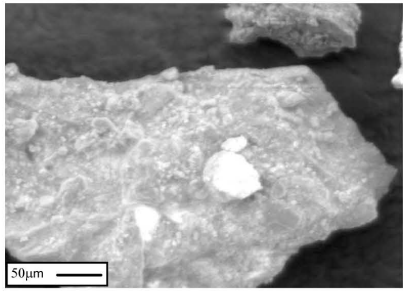

Ruthner dust

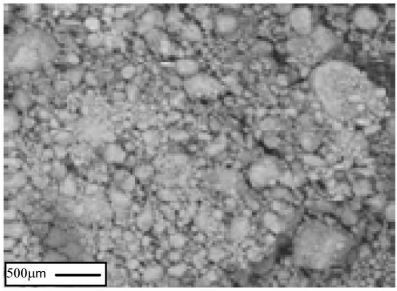

Blast furnace sludge

Figure 1. Microphotographs of metallurgical wastes studied (OM photos above and SEM photos below).

Table 1. Semi-quantitative chemical analysis (EDS) of the wastes.

\begin{tabular}{cccccccccccc}
\hline Waste & $\mathrm{Na}$ & $\mathrm{Mg}$ & $\mathrm{Al}$ & $\mathrm{Si}$ & $\mathrm{S}$ & $\mathrm{Cl}$ & $\mathrm{K}$ & $\mathrm{Ca}$ & $\mathrm{Mn}$ & $\mathrm{Fe}$ \\
\hline FS & 7.1 & 4.9 & 14.7 & 62.8 & --- & --- & 0.5 & 1.1 & --- & 8.9 \\
CSS & --- & 6.8 & 5.4 & 8.1 & --- & --- & --- & 53.1 & 3.9 & 22.7 \\
RD & --- & --- & 0.8 & 1.2 & --- & 0.5 & --- & --- & 0.9 & 96.6 \\
BFS & 19.0 & 1.3 & 13.1 & 30.7 & 8.7 & 1.2 & 0.6 & 1.0 & 6.7 & 17.7 \\
\hline
\end{tabular}



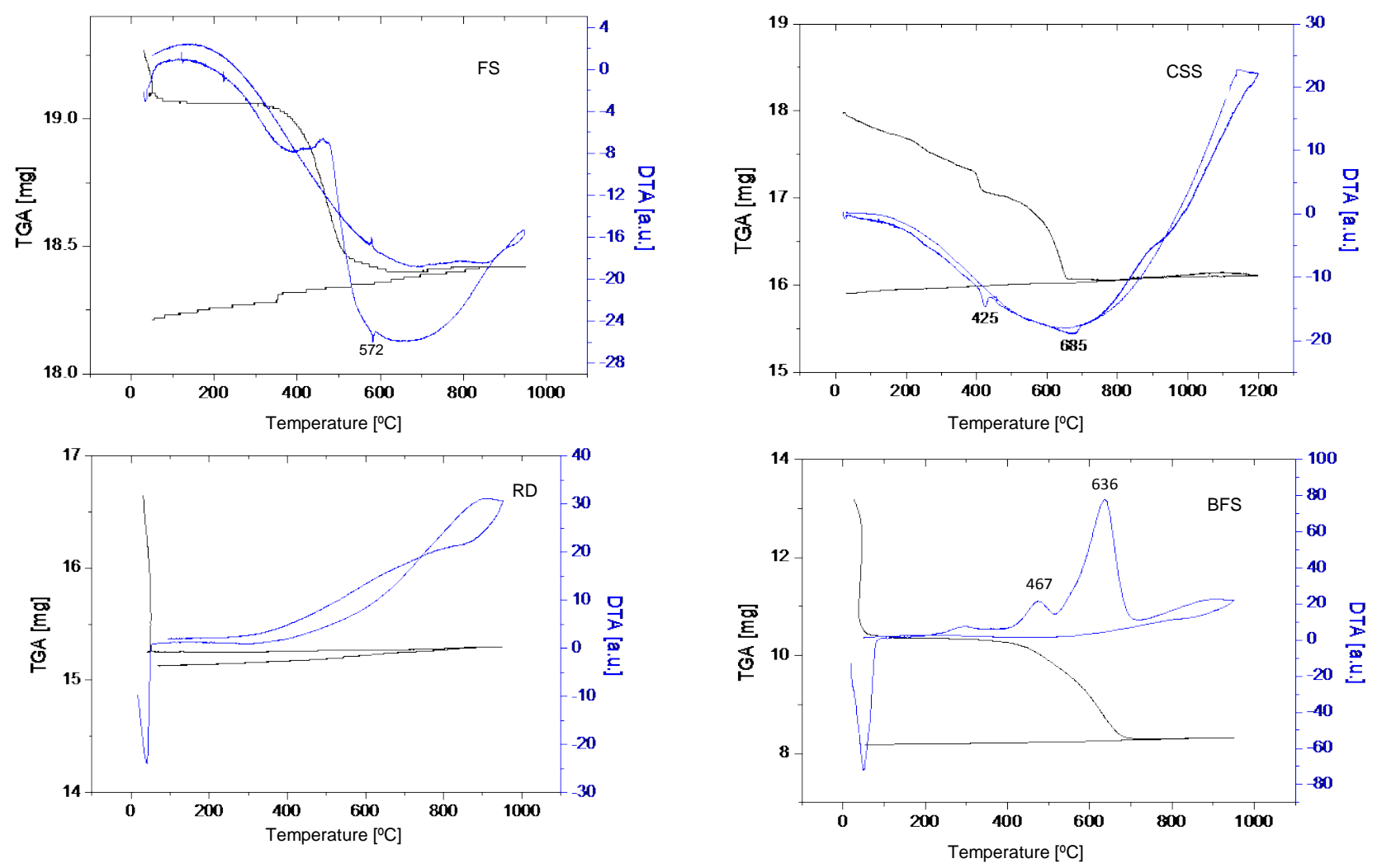

Figure 2. DTA-TGA analysis of the studies wastes.

CSS sample presents two ranges with weight losses $400^{\circ} \mathrm{C}-430^{\circ} \mathrm{C}$ and $600^{\circ} \mathrm{C}-700^{\circ} \mathrm{C}$ ranges, and the corresponding endothermic reactions in the DTA at maximum temperatures of $425^{\circ} \mathrm{C}$ and $685^{\circ} \mathrm{C}$. They are interpreted as calcium hydroxide and carbonate decompositions respectively.

In BFS waste, there is a constant weight loss between $400^{\circ} \mathrm{C}$ to $700^{\circ} \mathrm{C}$ which can be attributed to the combustion of carbonaceous materials of the sample. DTA analysis shows two exothermic peaks at $467^{\circ} \mathrm{C}$ and $636^{\circ} \mathrm{C}$. They are interpreted as exothermic oxidation reaction from $\mathrm{Fe}_{3} \mathrm{O}_{4}$ and $\mathrm{FeO}$ (determined by XRD) to $\mathrm{Fe}_{2} \mathrm{O}_{3}$, which is the only oxide detected by XRD in the calcined sample [14].

In RD sample, neither weight loss nor peaks have been found in DTA analysis. This result was expected taking into account the results of XRD that indicate the presence of $\mathrm{Fe}_{2} \mathrm{O}_{3}$ alone and the results of the weight loss ignition essay.

The samples were prepared with the wastes as received, selecting particle sizes less than $2 \mathrm{~mm}$. The particle size distribution of the powders is shown in Figure 3.

\subsection{Ceramic Products Characterization}

Samples obtained with addition of CSS and BFS waste sintered at $950^{\circ} \mathrm{C}$ and those prepared with foundry sands

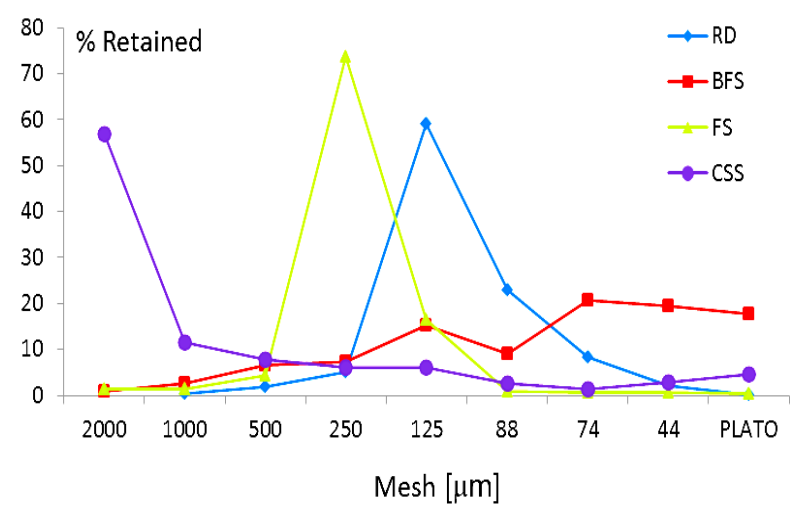

Figure 3. Particle size distribution of the materials.

sintered at $900^{\circ} \mathrm{C}$. Samples containing up to $20 \%$ residue $\mathrm{RD}$ sintered at $950^{\circ} \mathrm{C}$, while those with higher RD contents did at $1000^{\circ} \mathrm{C}$. Figure 4 shows some of the obtained products.

The samples are usually maintained at room temperature and humidity during the characterization process. It was noted that after a period of two weeks the samples with contents greater than $10 \%$ of CSS showed shelling of the structure and presented white areas, attributed to the formation of hydroxides of $\mathrm{Ca}$ and $\mathrm{Mg}$, which implies that these samples are not stable even after sintering. 
The porosity of the samples obtained adding BFS, FS and RD is shown in Figure 5. The corresponding results are in the required commercial range.

The porosity of the samples with CSS couldn't be determined because the samples were shelled during the corresponding test.

The test results of flexural strength are shown in Figure 6. In general these values are below those required for tiles.

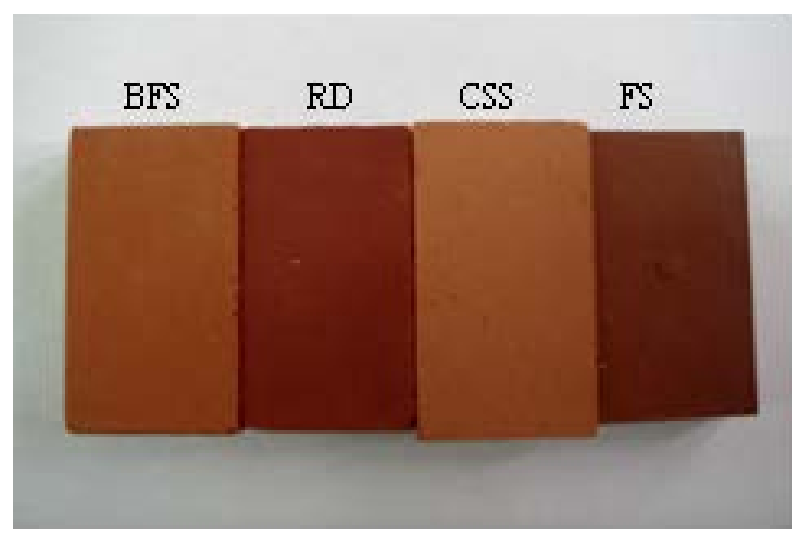

Figure 4. Sintered products.

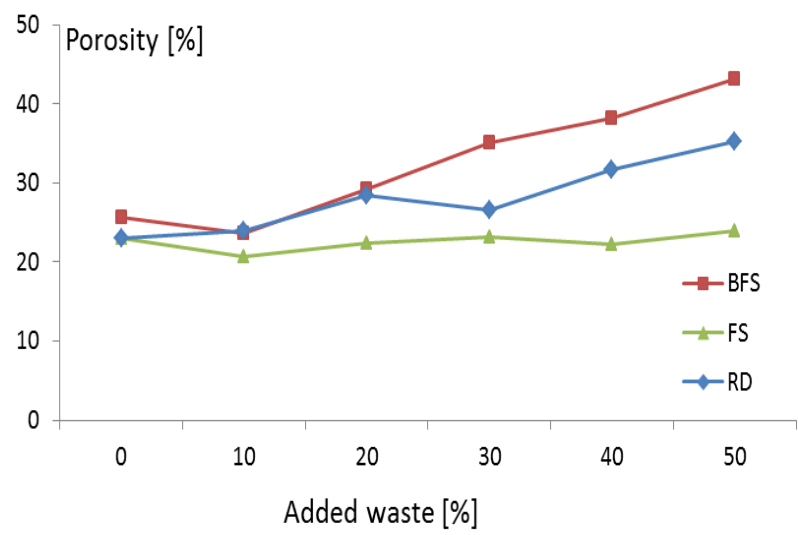

Figure 5. Porosity of the samples.

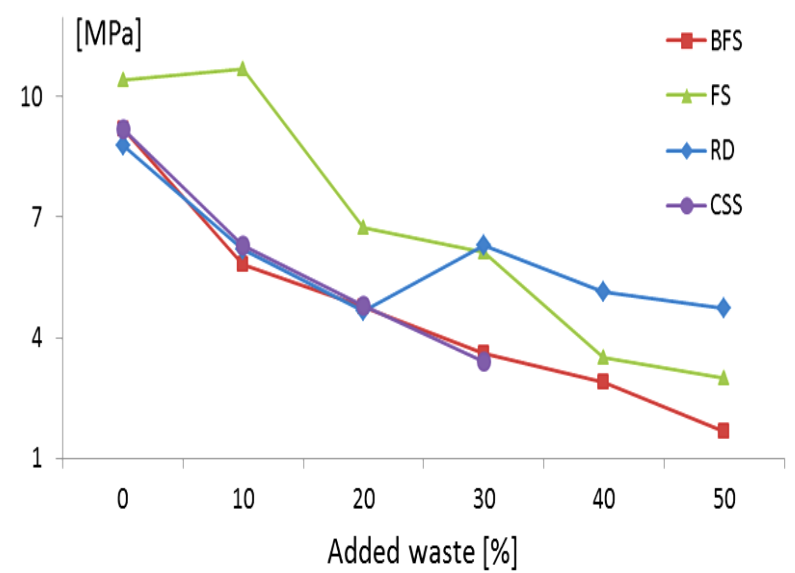

Figure 6. Flexural modulus of rupture.
The required compressive strength for building blocks, clay based, is more than 10.3 MPa, 17.2 MPa and 20.7 $\mathrm{MPa}$ for environmental requirements (temperature and humidity) low, moderate and severe respectively, according to ASTM C62-04. Compressive strength higher than 10.0 MPa is set by Spanish standards for this type of ceramic (NSE FL90-Royal Decree 1723/1990).

All the samples show values higher than those established by the standards, except those with higher BFS content. These results lead to the conclusion that there is a high feasibility of reuse of this type of waste as raw material for ceramic masonry, since the flexural requirements are lower.

The permanent volumetric variation (PVV) and the weight loss on ignition (LoI) of the samples are presented in Figures 7 and 8, respectively.

The PVV of the samples with added BFS is greater than that obtained for the clay except for the samples with 40 and $50 \%$ of added waste having a similar and slightly superior PVV, respectively.

The samples with lower RD contents show PVV values similar to those of the clay whereas above $20 \%$ of waste addition, variations in direct relation to discard content were determined. It is observed a maximum decrease of approximately $12 \%$ for samples with $50 \%$ of RD. Despite

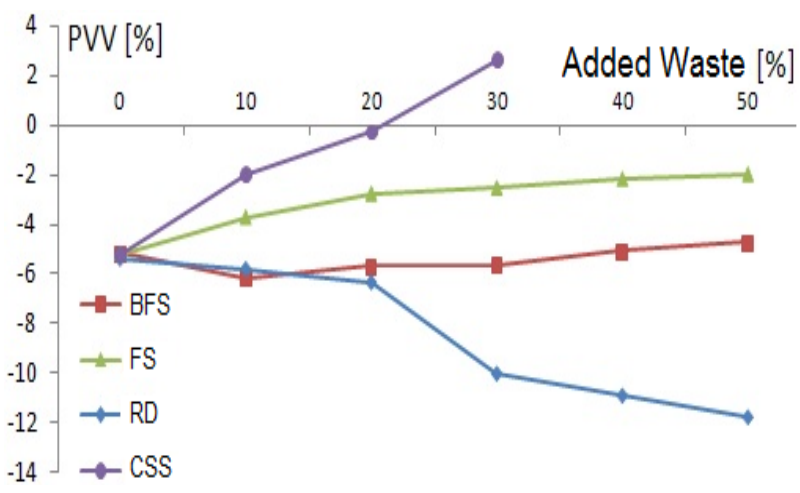

Figure 7. Permanent volumetric variation.

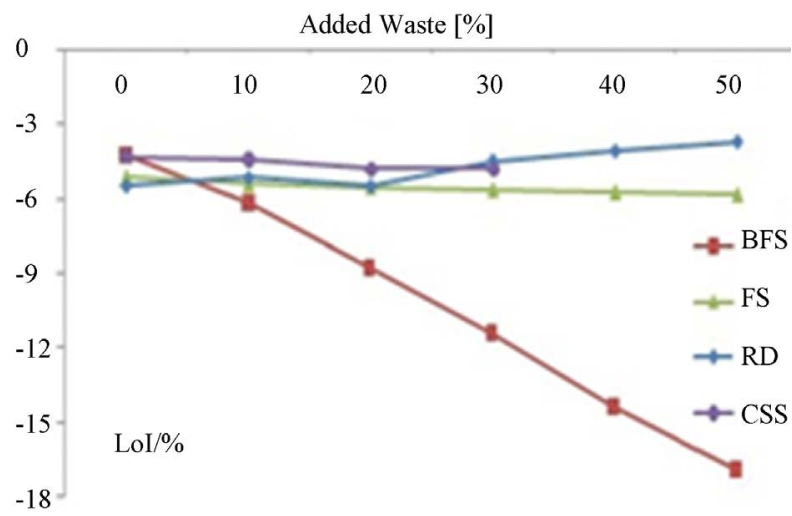

Figure 8. Weight loss on ignition of the samples. 
being a high value of volumetric variation, these samples show no cracking or visible macroscopic cracks.

The higher weight loss on ignition is registered for the samples with higher content of BFS waste.

The highest LoI is $16.9 \%$ for the samples with $50 \%$ BFS. The lowest LoI is registered for the sample with highest RD content.

\section{Conclusions}

This paper discusses the feasibility of utilization of metallurgical wastes as raw material for ceramic industry in tiles and masonry production. Wastes used as aggregates in clay based ceramics were blast furnace sludge, converter steel slag, Ruthner dust and foundry sand.

The results suggest that with the exception of the slag, the analyzed wastes can be incorporated as raw material replacement in the production processes of ceramic compact.

\section{Acknowledgements}

The authors wish to thank the Commission of Scientific Researches of Buenos Aires Province, Argentina, and National Agency of Technological and Scientific Promotion, Argentina, for the financial supports received for this work.

\section{REFERENCES}

[1] Z. Ismail and E. Al-hashmi, "Reuse of Waste Iron as a Partial Replacement of Sand in Concrete," Waste Management, Vol. 28, No. 11, 2008, pp. 2048-2053. http://dx.doi.org/10.1016/j.wasman.2007.07.009

[2] R. Siddique, G. Schutter and A. Noumowe, "Effect of UsedFoundry Sand on the Mechanical Properties of Concrete," Construction and Building Materials, Vol. 23, No. 2, 2009, pp. 976-980. http://dx.doi.org/10.1016/j.conbuildmat.2008.05.005

[3] R. Magnani Andrade, S. Cava, S. Nascimento Silva, L. Bastos Soledade, C. Rossi, E. Leite, C. Paskocimas, J. Varela and E. Longo, "Foundry Sand Recycling in the Troughs of Blast Furnaces: A Technical Note,” Journal of Materials Processing Technology, Vol. 159, No. 1, 2005, pp. 125-134. http://dx.doi.org/10.1016/j.jmatprotec.2003.10.021

[4] F. Raupp-Pereira, M. Ribeiro, A. Segadaes and J. Labrincha, "Extrusion and Property Characterisation of WasteBased Ceramic Formulations," Journal of the European Ceramic Society, Vol. 27, No. 5, 2007, pp. 2333-2340. http://dx.doi.org/10.1016/j.jeurceramsoc.2006.07.015
[5] B. Das, S. Prakash, P. S. R. Reddy and V. N. Misra, “An Overview of Utilization of Slag and Sludge from Steel Industries," Conservation and Recycling, Vol. 50, No. 1, 2007, pp. 40-57.

http://dx.doi.org/10.1016/j.resconrec.2006.05.008

[6] J. Waligora, D. Bulteel, P. Degrugilliers, D. Damidot, J. L. Potdevin and M. Measson, "Chemical and Mineralogical Characterization of LD Converter Steel Slag: A MultiAnalytical Techniques Approach," Materials Characterization, Vol. 61, No. 1, 2010, pp. 39-48. http://dx.doi.org/10.1016/j.matchar.2009.10.004

[7] Y. L. Chen, J. E. Chang, P. H. Shih, M. S. Ko, Y. K. Chang and L. C. Chiang, "Reusing Pretreated Desulfurization Slag to Improve Clinkerization and Clinker Grindability for Energy Conservation in Cement Manufacture,” Journal of Environmental Management, Vol. 91, No. 9, 2010, pp. 1892-1897. http://dx.doi.org/10.1016/j.jenvman.2010.04.006

[8] E. Furlani, G. Tonello and S. Maschio, "Recycling of Steel Slag and Glass Cullet from Energy Saving Lamps by Fast Firing Production of Ceramics," Waste Management, Vol. 30, No. 8-9, 2010, pp. 1714-1719. http://dx.doi.org/10.1016/j.wasman.2010.03.030

[9] W. F. Kladnig, "New Development of Acid Regeneration in Steel Pickling Plants," Journal of Iron and Steel Research, Vol. 15, No. 4, 2008, pp. 1-6. http://dx.doi.org/10.1016/S1006-706X(08)60134-X

[10] A. López-Delgado, C. Pérez and F. A. López, "The Influence of Carbon Content of Blast Furnace Sludges and Coke on the Adsorption of Lead Ions from Aqueous Solution," Carbon, Vol. 34, No. 3, 1996, pp. 423-426. http://dx.doi.org/10.1016/0008-6223(96)87611-1

[11] A. López-Delgado, C. Pérez and F. A. López, "Sorption of Heavy Metals on Blast Furnace Sludge,” Water Research, Vol. 32, No. 4, 1998, pp. 989-996. http://dx.doi.org/10.1016/S0043-1354(97)00304-7

[12] S. Li, J. Cui, Q. Zhang, J. Fu, J. Lian and C. Li, "Performance of Blast Furnace Dust Clay Sodium Silicate Ceramic Particles (BCSCP) for Brewery Wastewater Treatment in a Biological Aerated Filter,” Desalination, Vol. 258, No. 1-3, 2010, pp. 12-18. http://dx.doi.org/10.1016/j.desal.2010.04.006

[13] L. P. Davila, S. H. Risbud and J. F. Shakelford, "Quartz and Silicas. Chapter 5,” In: J. F. Shackelford and R. H. Doremus, Eds., Ceramic and Glass Materials, Springer, 2008, p. 73.

[14] C. F. Vieira, P. Andrade, G. Maciel, F. Vernilli and S. Monteiro, "Incorporation of Fine Steel Sludge Waste into Red Ceramic,” Material Science and Engineering A, Vol. 427, No. 1-2, 2006, pp. 142-147. http://dx.doi.org/10.1016/j.msea.2006.04.040 